\title{
Habilidades socioemocionais na escola: guia prático da educação infantil ao ensino fundamental, Roseli Bonfante Curitiba: Juruá Editora, 2019. 91 p.
}

Priscila Kely da Rocha

Mestranda do Programa de Mestrado Profissional em Gestão e Práticas Educacionais pela Universidade Nove de Julho (Progepe/Uninove). Graduada em Pedagogia com especialização em

Psicopedagogia Institucional. Atua como docente de Educação Infantil na Rede Municipal de

Guarulhos.

Universidade Nove de Julho (Uninove) São Paulo - SP - Brasil priscilar443@gmail.com

Lígia de Carvalho Abões Vercelli

Doutora e Mestra pelo Programa de Pós-Graduação em Educação da Universidade Nove de Julho (PPGE/Uninove). Graduada em Psicologia e em Pedagogia com especialização em Psicopedagogia e Psicanálise. Atua como docente no curso de Pedagogia e no Programa de Mestrado em Gestão e Práticas Educacionais da Universidade Nove de Julho

(Progepe/Uninove). vercelli.ligia@gmail.com

Roseli Bonfante é graduada em Psicologia pela Universidade para o Desenvolvimento do Alto Vale do Itajaí (Unidavi), é especialista em Terapia Cognitiva pelo Instituto Catarinense de Terapia Cognitiva (ICTC) e em Terapia Cognitivo-Comportamental na Infância e Adolescência pelo Instituto Paranaense de Terapia Cognitiva (IPTC). É mestranda no programa de Mestrado Profissional em Educação Profissional e Tecnológica do Instituto Federal Catarinense (ProfEPTIFC) e atua como servidora pública na Secretaria Municipal de Educação na cidade de Rio do Sul, no interior de Santa Catarina.

A obra Habilidades socioemocionais na escola produzida por Bonfante resulta de sua experiência profissional dedicada ao desenvolvimento de um projeto de saúde mental para o pleno crescimento socioemocional de crianças de 4 a 6 anos, etapa da Educação Infantil, e de alunos de 10 e 11 anos de idade, que cursam o Ensino Fundamental, em uma cidade do interior de Santa Catarina.

A obra é dividida em quatro capítulos nos quais a autora aborda o projeto, tomando como base para sua argumentação autores como Caminha, Goleman, Matos, entre outros. 
Ressalta sua motivação para a elaboração do projeto, suas reflexões e ações coerentes com as práticas de Psicologia aplicada à Educação.

$\mathrm{Na}$ introdução, Bonfante sinaliza com que intensidade, e por quanto tempo, as emoções foram negligenciadas e vistas como processos separados e independentes no indivíduo. A autora nos esclarece que, no passado, a emoção não era vista como algo que a escola precisasse se preocupar, contudo, atualmente, a educação socioemocional vem ganhando espaço no contexto escolar. Traz estudos como os apontados por Nunes (2009), que mostram a criança como um sujeito integral em seu processo de desenvolvimento, e assim deve ser explorada pela escola, ou seja, como um corpo físico, intelectual, social e emocional. Afirma que a escola deve contribuir para que a criança aperfeiçoe sua autoconfiança, maneje suas emoções, controle seus impulsos, promova e aumente a empatia e a resiliência de forma eficaz, adequada e saudável, de maneira que apresente uma melhoria significativa em seu desenvolvimento cognitivo, mental e social.

No primeiro capítulo intitulado "Breve nota sobre emoções e sentimentos", a autora apresenta as contribuições da Psicologia, da Biologia e da Neurociência para o estudo das emoções, citando que reações fisiológicas e cognições produzem estados mentais que são percebidos como agradáveis ou desagradáveis, cujo resultado pode ser chamado de emoção. Destaca como esses processos ocorrem e que são naturalmente a essência do ser humano.

À luz de diversos autores, conceitua as emoções primárias, como medo, raiva, tristeza, alegria, amor, nojo, e emoções secundárias, como culpa, vergonha, decepção, saudade, solidão, preocupação, explicando como acontecem suas funções, os eventos ambientais que as impulsionam, o que advém de seu excesso ou falta, as experimentações fisiológicas da ocorrência de cada emoção e sua função adaptativa.

Apresenta os primeiros estudos sobre inteligência emocional, tratada na Psicologia, definida como a capacidade de reconhecer os próprios sentimentos e os dos outros, assim como a habilidade de lidar com eles. Ressalta como os estudos ficaram amplamente conhecidos em 1995 nos livros Inteligência emocional, de Daniel Goleman, e O erro de Descartes, de António R. Damásio. Aponta que esses dois autores se baseiam em estudos anteriores de Peter Salovey e John Mayer sobre inteligência emocional e ampliam suas pesquisas a respeito da capacidade do sujeito de criar motivação para si mesmo, de persistir no objetivo apesar das dificuldades, de controlar os impulsos, de adiar satisfações, de ser empático, autoconfiante e conter a ansiedade. Sugerem também que as habilidades e aptidões emocionais são aprendidas e aprimoradas desde a mais tenra idade. Daí surge a necessidade da Educação Emocional como forma de auxiliar a criança na busca por estratégias para o manejo adequado e hábil de suas emoções. 
ROCHA, Priscila Kely da; VERCELLI, Lígia de Carvalho Abões. Habilidades socioemocionais na escola: guia prático da educação infantil ao ensino fundamental, Roseli Bonfante.

No segundo capítulo, “O desenvolvimento socioemocional na criança”, a autora aponta, com base em BEE (2003) e Brazelton (1994), como paulatinamente a criança adquire consciência de suas emoções, sendo um dos aspectos mais importantes desse desenvolvimento a modulação e a regulação de suas expressões emocionais por meio das conversas que entabula, bem como orientações no tocante aos comportamentos adequados e inadequados. As regras sociais de expressão emocional têm aprendizado tácito a partir de sinais observados no ambiente. Perceber emoções em si própria e nos outros são habilidades importantes e necessárias para que a criança tenha boas relações sociais e essas competências devem ser estimuladas.

No capítulo terceiro, "Educação socioemocional na Educação Infantil: os professores como promotores de saúde mental", Bonfante relata as experiências do trabalho desenvolvido por professores da Educação Infantil a partir do projeto apresentado a eles pela autora, mediante as formações continuadas na cidade de Rio do Sul, cujo objetivo foi aumentar a saúde e o bemestar global das crianças. Elencaram-se os objetivos norteadores do trabalho cujo foco foram as emoções sob a premissa de que a criança atuasse como protagonista de sua evolução, capaz de criar, interpretar, colocando em ação diferentes linguagens, esquemas afetivos, cognitivos, sociais, motores e estéticos. Sempre partindo de situações reais dentro de um contexto significativo para ela.

No ano de 2014, a autora iniciou uma formação com professores de Educação Infantil da rede municipal de Rio do Sul sob o título de "Emoções e educação socioemocional", que abrangia trinta e um Centros de Educação Infantil e atingia 3362 crianças. Após a formação, as professoras passaram a pôr em prática as atividades propostas com crianças de quatro a seis anos e construíram portfólios que foram apresentados e discutidos nos encontros formativos. As atividades foram ministradas nos contextos de sala de aula dentro de temáticas que as professoras já vinham praticando com suas turmas alinhadas às propostas do projeto Educação Socioemocional. Assim, algumas professoras usaram as ideias de atividades dessa temática nos projetos que já estavam desenvolvendo e que serviram de base para compor atividades relacionadas às emoções; outras, optaram por realizar oficinas e momentos conversando especificamente sobre o tema com as crianças.

Ainda nesse capítulo, a autora nos apresenta a forma como a temática "emoções" é inserida nos diversos projetos nas escolas onde o projeto maior aconteceu. Aponta como ele foi aplicado nas oficinas e a maneira como o conceito foi abordado, tendo a roda de conversa e as percepções da criança como pontos de partida. O momento de desenvolvimento das crianças e 
sua capacidade de abstração dos conceitos a respeito das emoções também foi levado em conta, trabalhando-se as emoções primárias com as crianças pequenas.

A autora entende que o trabalho com Habilidades Socioemocionais deva acontecer nas escolas de forma contínua, para além do projeto, a fim de que os resultados sejam percebidos a médio e a longo prazo, pois trata-se de construir, num processo paulatino e reflexivo, conhecimentos cada vez mais complexos acerca das emoções e sentimentos; porém, ainda nos encontros formativos, as professoras trazem nos portfólios relatos e depoimentos de suas percepções sobre o modo como as crianças avançaram na compreensão e reconhecimento de seus próprios sentimentos e de seus colegas.

No quarto capítulo, "Ciranda das emoções: um projeto de promoção de saúde para estudantes do Ensino Fundamental", como o próprio título evidencia, a autora apresenta um relato de sua experiência na implantação do projeto nas escolas municipais de Rio do Sul, porém agora com uma nova estruturação voltada ao Ensino Fundamental, especificamente com crianças dos quintos anos. Bonfante ressalta, a princípio, um panorama da temática das emoções em modelos internacionais como Reino Unido e Estados Unidos. Descreve o Programa de Ensino de Habilidades de Vida que foi proposto pela Organização Mundial da Saúde (OMS) e adaptado para a população brasileira, enfatizando que a escola, com seu papel social, é o melhor cenário para o desenvolvimento integral da criança, resultando na minimização da desigualdade e contribuindo, assim, para uma cidadania plena.

Com a ampliação do projeto, ajustado para atender também a essa etapa de ensino, e visando ao momento de desenvolvimento das crianças maiores, caracterizadas por outras subjetividades, o trabalho ganha novos contornos, e ganha uma equipe multidisciplinar. Entretanto, a essência do trabalho é mantida, com as oficinas semanais no contexto escolar objetivando potencializar as habilidades sociais, emocionais de todos os envolvidos.

Com esse grupo, surgem temáticas como: civilidade, assertividade, solução de problemas interpessoais, resiliência, autocontrole, empatia e expressividade emocional, destacando a contribuição para a formação de sujeitos críticos com habilidades para lidar de maneira apropriada com suas emoções e sentimentos, capazes de lidar com a frustração e ansiedade, colocando-se no lugar do outro, sendo colaborativos e responsáveis, respeitando a diversidade com altruísmo e otimismo.

Nessa obra, Roseli Bonfante nos apresenta o resultado empírico e positivo de seu trabalho nas escolas da rede municipal de Rio do Sul, ciosa da relevância de estudos que tratam de questões do desenvolvimento da criança de forma integral, não apenas considerando o sujeito 
ROCHA, Priscila Kely da; VERCELLI, Lígia de Carvalho Abões. Habilidades socioemocionais na escola: guia prático da educação infantil ao ensino fundamental, Roseli Bonfante.

cognitivo, mas percebendo a importância de edificar nele competências sociais e afetivas. De forma agradável e didática, a autora apresenta seu projeto desde o espaço formativo com professores, e seus desdobramentos, até os primeiros resultados de sua implementação. O caráter prático e interventivo de sua obra evidencia a necessidade do aprofundamento de pesquisas e contribui no alinhamento de velhas práticas dos educadores às novas propostas educacionais.

Recebido em: 15 jun. 2020 / Aprovado em: 06 jul. 2020

\section{Cite como:}

\section{(ABNT NBR 6023:2018)}

ROCHA, Priscila Kely da; VERCELLI, Lígia de Carvalho Abões. Habilidades socioemocionais na escola: guia prático da educação infantil ao ensino fundamental, Roseli Bonfante. Dialogia, São Paulo, n. 35, maio/ago. 2020. Resenha, p. 283-287. Disponível em: https://doi.org/10.5585/dialogia.n35.17437.

\section{American Psychological Association (APA)}

Rocha, P. K., \& Vercelli, L. de C. A. (2020, maio/ago.). Habilidades socioemocionais na escola: guia prático da educação infantil ao ensino fundamental, Roseli Bonfante. Resenha. Dialogia, São Paulo, 35, p. 283-287. https://doi.org/10.5585/dialogia.n35.17437. 